\title{
Oestradiol: any role in cardiovascular risk factors in female centenarians of Hainan?
}

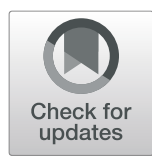

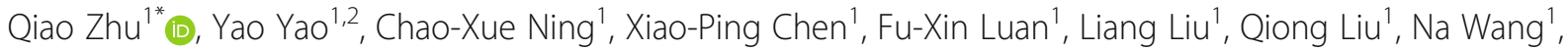
Fu Zhang ${ }^{1}$ and Ya-Li Zhao ${ }^{1 *}$

\begin{abstract}
Background: Previous studies reported that low level of oestradiol (E2) was associated with higher risk of cardiovascular disease (CVD). However, little study examined the relationship between E2 and CVD in longevous women, which were deficient in serum E2 for the post-menopausal status. Therefore, this study aims to explore the association between E2 and CVD risk factors in a group of female centenarians of Hainan, China.

Methods: A total of 413 female centenarians (aged from 100 to 115) from China Hainan Centenarian Cohort Study (CHCCS) were enrolled in this study. Home interviews were conducted to collected data on demographic characteristics, health-related lifestyles, and anthropometrics. The level of serum E2 was assessed in the Clinical Laboratory of Hainan branch of PLA General Hospital. The variables of CVD risk factors, including blood pressures, lipids and blood glucose, were measured through standard procedures.

Results: Significant negative correlations between levels of serum E2 and TC, HDL-C, and LDL-C were observed in this study. Compared with the highest group of E2, the odds ratio and 95\% confidence intervals of high LDL-C in groups 3, 2 and 1 were OR1.94 (CI0.82-4.62), OR3.61 (Cl1.27-10.25) and OR9.29 (Cl2.08-41.53), respectively. Similarly, the prevalence of hypertension was decreased with the increase of serum E2. The odds ratio and 95\% confidence intervals of stage-2 hypertension in groups 3, 2 and 1 versus highest E2 group were OR1.34 (CI0.49-3.72), OR1.36 (CI0.47-3.99) and OR1.38 (CI0.45-4.20), respectively.

Conclusions: This study examined the relationship between E2 and CVD risk factors in a group of communitybased female centenarians. A negative correlations between serum E2 levels and CVD risk factors, i.e. high level of LDL-C, TC, and hypertension were observed in this population. Besides, the level of serum E2 is also negatively correlated with HDL-C. Further studies on the correlation between serum E2 and CVD risk factors, especially dyslipidemia, in longevous and post-menopausal women are warranted.
\end{abstract}

Keywords: Centenarians, Women, Oestradiol, Cardiovascular disease, Dyslipidemia

\section{Background}

The number of Chinese centenarians, according to the data from China CENSUS, has increased from 17,877 to 35,954 between 2000 and 2010. And Hainan province has the fastest growth rate of centenarians, with an increase of $254 \%$ from $3.78 / 100,000$ to $13.4 / 100,000$. Currently, studies suggested that centenarians are a template for healthy aging to cope with global ageing and steadily improve their life expectancy $[1,2]$.

\footnotetext{
*Correspondence: zhuqiao2006@163.com; zhaoyl301@163.com

'Hainan branch of PLA General Hospital, Sanya 572000, China

Full list of author information is available at the end of the article
}

Historical demographic data from 37 countries revealed that women live longer than men. In industrialized countries, gender gap in life expectancy ranges from approximately 4 to 10 years. The gap may be related to sex hormones [3]. Moreover, there are significant differences in sex hormone levels between pre-menopausal and postmenopausal women, and the incidence of CVD in postmenopausal women is significantly increased [4]. This suggests that sex hormones play an important role in the development of CVD. Actually, CVD is one of the most serious causes of death in the elderly. Epidemiological studies have shown that sex hormones are associated with CVD risk factors, such as

(c) The Author(s). 2019 Open Access This article is distributed under the terms of the Creative Commons Attribution 4.0 International License (http://creativecommons.org/licenses/by/4.0/), which permits unrestricted use, distribution, and 
BP, TC, TG, HDL-C and LDL-C. However, there are few studies on female centenarians.

Hainan province is an independent island. Due to historical and economic factors, centenarians are indigenous, and show a natural aging process. This study explored the relationship between E2 and CVD risk factors among female centenarians in Hainan, providing basic data and theoretical support for healthy aging.

\section{Methods}

\section{Methods}

A cross-sectional study was conducted between June 2014 and March 2016. We investigated 413 female centenarians from 18 regions throughout Hainan province. All are native settlers.

The surveyors were strictly trained before investigation, and the survey content, operative procedure and methods were standardized. Height $(\mathrm{H})$, weight $(\mathrm{W})$, waist circumference (WC) and hip circumference (HC) were measured with participants dressed in light clothing and barefoot. We measured the height and weight of the elderly with a scale (Seca, Germany). Each parameter was measured twice. We computed the BMI and WHR using the following standard formula: $\mathrm{BMI}=\mathrm{W} / \mathrm{H}^{2}$, $\mathrm{WHR}=\mathrm{WC} / \mathrm{HC}$.

In the sitting position, we measured the blood pressure of the centenarians two times by electronic sphygmomanometers (Omron Hem-7200, Japan). At least 1-min intervals between the measurements, and the reported blood pressures were the average of the two measurements. If the difference between the first and second measurement was more than $5 \mathrm{mmHg}$, the repeated measurements were performed.

Samples of venous blood were extracted from the centenarians and transported within $4 \mathrm{~h}$ in chilled bio-transport containers $\left(4^{\circ} \mathrm{C}\right)$ to clinical laboratory. The estradiol III kit (Roche) was used to detect fresh serum estradiol levels in female centenarians by electrochemiluminescence (Cobas E602). The lower detection threshold of the kit was $18.4 \mathrm{pmol} / \mathrm{L}$. The fresh plasma TC, HDL-C and LDL-C levels were measured by enzyme colorimetry (Cobas C701) using Cholesterol Gen.2 kit, HDL-Cholesterol plus 3rd generation kit, and LDL-Cholesterol Gen.3 kit respectively. The content of fresh plasma TG was determined by colorimetry (Cobas C701) using Triglycerides kit (Roche). Fresh plasma glucose was examined by hexokinase method (Glucose HK Gen.3 kit, Cobas C701).

\section{Definition of CVD risk factors}

The 2017 Hypertension Clinical Practice Guidelines provided a new categorization of BP levels. This guideline defined BP categories of normal, elevated, or stage 1 or 2 hypertension. SBP/DBP thresholds of $130 / 80 \mathrm{mmHg}$ now define the diagnosis of "stage 1 hypertension", and $140 / 90 \mathrm{mmHg}$ define the diagnosis of "stage 2 hypertension" [5]. As for plasma glucose, we use the reference range provided in the reagent instructions, 4.16-6.72 mmol/L (> 90 years old) (Glucose HK Gen.3 kit, Roche Diagnostics, North America).

The cut-off points for dyslipidemia were plasma $\mathrm{TC} \geq$ $240 \mathrm{mg} / \mathrm{dl}$ and/or use of medications to lower blood cholesterol for high TC, TG $\geq 200 \mathrm{mg} / \mathrm{dl}$ for high TG, HDL-C $<40 \mathrm{mg} / \mathrm{dl}$ for low HDL-C, and LDL-C $\geq 160 \mathrm{mg} /$ $\mathrm{dl}$ and/or use of medications to lower blood cholesterol for high LDL-C.

\section{Ethical approval}

The study protocol was approved by the ethical committee of the Hainan branch of PLA General Hospital (Sanya, China). Each participant provided written informed consent to be included in the study.

\section{Data management}

All paper-based information was stored in the data cabinet and managed by specific personnel. The data validity was checked by hand on a unified model. Then, we used Epidata 3.0 software to enter the data twice, and SPSS 19.0 software (SPSS Inc., Chicago, IL, USA) was used for statistical analysis.

\section{Statistical analysis}

Descriptive data were shown as the mean \pm SD. By multiple linear regression analysis, we analyzed the relationship between E2 and physical examination adjusted for BMI, WC, WHR, SBP, DBP, glucose, TC, TG, HDL-C and LDL-C. With the increase of variables, we presented a cumulative R2. Multiple logistic regression was used to evaluate the association between E2 and CVD risk factors adjusted for age, BMI, WC, WHR and the number of children. A $P$-value $<0.05$ was considered statistically significant.

\section{Results \\ General information of female centenarians}

A total of 413 female centenarians completed the survey. We collected basic information from the standardized questionnaires. The results showed that all participants were married, and $97.1 \%$ of centenarians engaged in physical labour. $55.7 \%$ of the elderly lived in the countryside, while $44.3 \%$ in the urban area. As for the number of children, $2.4 \%$ of the subjects had no children, $9.7 \%$ had one child and $87.9 \%$ had two or more children. Also, we measured the E2 and CVD risk factors, including body measurement variables (BMI, WC, WHR, SBP and DBP), blood glucose and lipids (TC, TG, HDL-C and LDL-C) in Table 1. 
Table 1 Characteristics of Study Subjects

\begin{tabular}{|c|c|c|}
\hline Variables & $N=413$ & Reference Range \\
\hline Age $($ mean $\pm S D)$ & $102.8 \pm 2.9$ & - \\
\hline $\mathrm{E} 2($ mean $\pm \mathrm{SD})$ & $46.99 \pm 28.86$ & 40-100 pmol/L \\
\hline $\mathrm{BMI}($ mean $\pm \mathrm{SD})$ & $17.69 \pm 3.67$ & $18.5-22.9$ \\
\hline$W C($ mean $\pm S D)$ & $75.13 \pm 8.95$ & $<80 \mathrm{~cm}$ \\
\hline WHR (mean $\pm S D)$ & $0.90 \pm 0.08$ & $<0.8$ \\
\hline $\mathrm{SBP}($ mean $\pm \mathrm{SD})$ & $154.46 \pm 24.77$ & $<130 \mathrm{mmHg}$ \\
\hline $\mathrm{DBP}($ mean $\pm \mathrm{SD})$ & $75.12 \pm 13.02$ & $<80 \mathrm{mmHg}$ \\
\hline glucose $($ mean $\pm S D)$ & $5.15 \pm 1.43$ & $4.16-6.72 \mathrm{mmol} / \mathrm{L}(>90$ years old $)$ \\
\hline $\mathrm{TC}($ mean $\pm \mathrm{SD})$ & $185.86 \pm 37.54$ & $<200 \mathrm{mg} / \mathrm{dl}$ \\
\hline $\mathrm{TG}($ mean $\pm \mathrm{SD})$ & $106.39 \pm 61.87$ & $<150 \mathrm{mg} / \mathrm{dl}$ \\
\hline $\mathrm{HDL}-\mathrm{C}($ mean $\pm \mathrm{SD})$ & $56.89 \pm 14.83$ & $>40 \mathrm{mg} / \mathrm{dl}$ \\
\hline $\mathrm{LDL}-\mathrm{C}($ mean $\pm \mathrm{SD})$ & $112.07 \pm 30.84$ & $<130 \mathrm{mg} / \mathrm{dl}$ \\
\hline
\end{tabular}

The relationship between E2 and physical examination By multiple linear regression analysis, we have found significant negative correlation between levels of E2 and TC, HDL-C, LDL-C, and no significant correlation between E2 and either SBP or DBP and also TG. However, after adjusting for BMI, WC, WHR, SBP, DBP, glucose, TC, TG, HDL-C and LDL-C, there was a positive correlation between E2 and TC (Table 2). As the number of variables increased, $\mathrm{R} 2$ gradually rose, indicating that the model was getting better. Furthermore, according to the level of E2, quartiles are used for grouping, named 1, 2, 3 and 4, respectively. It have shown significant negative correlation between E2 and TC, LDL-C (Fig. 1).

\section{The association between E2 and CVD risk factors}

Multiple logistic regressions was used to evaluate the association between E2 and CVD risk factors adjusted for age, BMI, WC, WHR and the number of children, as shown in Table 3. Compared with the highest group of $\mathrm{E} 2$, the odds ratio and 95\% confidence intervals of high
LDL-C in groups 3, 2 and 1 were OR1.94 (CI0.82-4.62), OR3.61 (CI1.27-10.25) and OR9.29 (CI2.08-41.53), respectively. Similarly, the prevalence of hypertension was decreased with the increase of serum E2. The odds ratio and $95 \%$ confidence intervals of stage- 2 hypertension in groups 3, 2 and 1 versus highest E2 group were OR1.34 (CI0.49-3.72), OR1.36 (CI0.47-3.99) and OR1.38 (CI0.45-4.20), respectively. And, high TC also showed a similar trend. However, it should be noted that there was no centenarians with high $\mathrm{TC}$ in the group 1 . So, the data in this column was absence. There were no significant correlation between E2 and the incidence of high TG, low HDL.

\section{Discussion}

Human longevity has an obvious tendency of maternal inheritance, and the average life expectancy of women in the world is higher than that of men [6]. With acceleration of China's population aging, the proportion of elderly women is increasing. Centenarian is a model of exceptional longevity [7]. So, we explored the relationship between E2 and cardiovascular risk factors through a study of 413 female centenarians in Hainan. Our results showed centenarians presented light weight [8], partly because of aging, which causes the structure and function decline of the organism, and partly because of E2, which reduces with ovarian recession and has an impact on glucose and lipid metabolism [9].

CVD is one of the leading causes of death worldwide, and it is more prevalent in postmenopausal women. Our results suggested that E2 was negatively correlated with LDL-C. E2 binds to receptors on hepatocytes, activates enzymes that affect lipid metabolism, promotes absorption of residual LDL by up-regulated LDL receptors, and accelerates the conversion of hepatic cholesterol to bile acids [10]. Moreover, E2, as a radical scavenger, is able to break the formation of free radical chains generated

Table 2 Multiple Linear Regression between E2 and Physical Examination

\begin{tabular}{|c|c|c|c|c|c|c|c|}
\hline variables & beta & $95 \% \mathrm{Cl}$ & $P$ & adjusted beta & $95 \% \mathrm{Cl}$ & $P$ & $R^{2}$ \\
\hline $\mathrm{BMI}$ & -0.097 & $-1.521 \sim-0.003$ & 0.049 & -0.122 & $-1.855 \sim-0.060$ & 0.037 & 0.009 \\
\hline WC & -0.014 & $-0.358 \sim 0.267$ & 0.775 & 0.156 & $0.009 \sim 0.995$ & 0.046 & 0.011 \\
\hline WHR & -0.051 & $-50.196 \sim 15.738$ & 0.305 & -0.137 & $-92.177 \sim-0.922$ & 0.046 & 0.018 \\
\hline SBP & -0.096 & $-0.224 \sim 0.000$ & 0.051 & -0.047 & $-0.189 \sim 0.080$ & 0.427 & 0.025 \\
\hline $\mathrm{DBP}$ & -0.066 & $-0.361 \sim 0.068$ & 0.179 & -0.014 & $-0.289 \sim 0.225$ & 0.808 & 0.026 \\
\hline Glucose & -0.033 & $-2.630 \sim 1.290$ & 0.502 & -0.045 & $-2.829 \sim 1.025$ & 0.358 & 0.028 \\
\hline $\mathrm{TC}$ & -0.205 & $-0.231 \sim-0.085$ & 0.000 & 0.449 & $0.060-0.631$ & 0.018 & 0.061 \\
\hline TG & -0.045 & $-0.066 \sim 0.024$ & 0.357 & -0.107 & $-0.105 \sim 0.006$ & 0.078 & 0.061 \\
\hline $\mathrm{HDL}-\mathrm{C}$ & -0.154 & $-0.486 \sim-0.113$ & 0.002 & -0.321 & $-0.933 \sim-0.316$ & 0.000 & 0.073 \\
\hline LDL-C & -0.198 & $-0.275 \sim-0.097$ & 0.000 & -0.566 & $-0.845 \sim-0.215$ & 0.001 & 0.098 \\
\hline
\end{tabular}

Adjusted for BMI, WC, WHR, SBP, DBP, concentrations of non-fast blood glucose, TC, TG, HDL-C and LDL-C. The first beta is the unadjusted values. E2 is used as a continuous variable in the model 

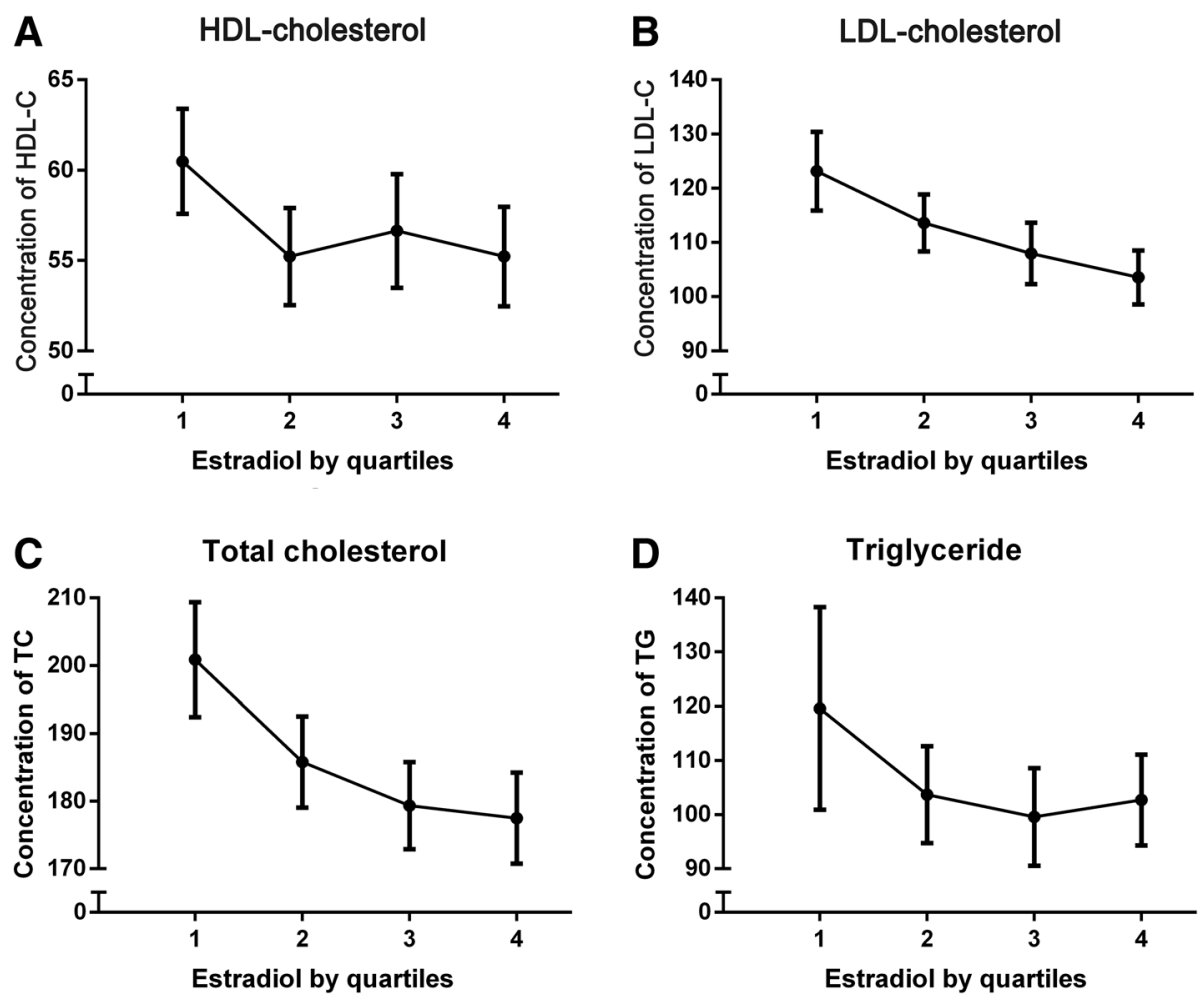

Fig. 1 Concentration of TC, TG, HDL-C, and LDL-C according to estradiol by quartiles. The concentrations of TC, TG, HDL-C, LDL-C were demonstrated as mean and $95 \% \mathrm{Cl}$ according to quartiles of estradiol (1st quartile: $\leq 19.4$, 2nd quartile: 19.5-40.3, 3rd quartile: 40.4-62.9, 4th quartile: $\geq 63.0$ )

Table 3 Multiple Logistic Regression between E2 and CVD Risk Factors

\begin{tabular}{|c|c|c|c|c|c|}
\hline Variable & & 1st quartile & 2nd quartile & 3rd quartile & 4th quartile \\
\hline & & & & & \\
\hline \multicolumn{6}{|c|}{ Hypertension } \\
\hline \multirow[t]{2}{*}{ Stage 1} & Unadjusted & $1.18(0.51-2.72)$ & $0.95(0.42-2.13)$ & $0.66(0.31-1.42)$ & 1.00 \\
\hline & Adjusted & $1.13(0.48-2.64)$ & $0.85(0.37-1.96)$ & $0.62(0.28-1.38)$ & 1.00 \\
\hline \multirow[t]{2}{*}{ Stage 2} & Unadjusted & $1.38(0.45-4.20)$ & $1.36(0.47-3.99)$ & $1.34(0.49-3.72)$ & 1.00 \\
\hline & Adjusted & $1.31(0.42-4.08)$ & $1.23(0.41-3.69)$ & $1.21(0.43-3.46)$ & 1.00 \\
\hline \multirow[t]{2}{*}{ High TC ${ }^{a}$} & Unadjusted & - & $5.60(1.83-17.10)^{* *}$ & $2.39(1.03-5.56)^{*}$ & 1.00 \\
\hline & Adjusted & - & $5.75(1.85-17.83)^{* *}$ & $2.34(0.99-5.50)$ & 1.00 \\
\hline \multirow[t]{2}{*}{ High TG } & Unadjusted & $1.43(0.44-4.66)$ & $3.68(0.75-18.17)$ & $1.82(0.52-6.43)$ & 1.00 \\
\hline & Adjusted & $1.51(0.43-5.31)$ & $3.88(0.74-20.48)$ & $1.71(0.45-6.55)$ & 1.00 \\
\hline \multirow[t]{2}{*}{ Low HDL } & Unadjusted & $1.88(0.61-5.81)$ & $3.08(1.07-8.91)^{* *}$ & $2.80(0.96-8.16)$ & 1.00 \\
\hline & Adjusted & $2.17(0.68-6.96)$ & $3.27(1.10-9.71)^{* *}$ & $3.17(1.05-9.51)^{* *}$ & 1.00 \\
\hline \multirow[t]{2}{*}{ High LDL } & Unadjusted & $9.29(2.08-41.53)^{* *}$ & $3.61(1.27-10.25)^{* *}$ & $1.94(0.82-4.62)$ & 1.00 \\
\hline & Adjusted & $10.22(2.22-46.98)^{* *}$ & $3.63(1.25-10.51)^{* *}$ & $1.83(0.76-4.43)$ & 1.00 \\
\hline
\end{tabular}

The prevalence of hypertension, high level of TC, TG, LDL-C and low level of HDL-C was demonstrated according to quartiles of estradiol

The cut-off points for dyslipidemia were plasma TC $\geq 240 \mathrm{mg} / \mathrm{dl}$ and/or use of medications to lower blood cholesterol for high TC, TG $\geq 200 \mathrm{mg} / \mathrm{dl}$ for high TG, $\mathrm{HDL}-\mathrm{C}<40 \mathrm{mg} / \mathrm{dl}$ for low HDL-C, and LDL-C $\geq 160 \mathrm{mg} / \mathrm{dl}$ and/or use of medications to lower blood cholesterol for high LDL-C

According to the level of E2, quartiles are used for grouping (1st quartile: $\geq 19.4,2$ nd quartile:19.5-40.3, 3rd quartile:40.4-62.9 4th quartile: $\geq 63.0$ ) The odds ratios were presented as unadjusted and further adjusted for age, BMI, WC, WHR and the number of children

${ }^{\text {a }}$ No centenarian with concentration of TC higher than $240 \mathrm{mg} / \mathrm{dl}$ in the first quartile thus the data was unavailable in this column

${ }^{*} P<0.05,{ }^{* *} P<0.01$ 
by the membrane oxidation processes, thereby inhibiting LDL and VLDL oxidation [11, 12]. Additionally, E2 can decrease the susceptibility of LDL-C to LDL oxidation, prevent the oxidative damage and protect the endothelial [13]. Also, we have found the incidence of high LDL-C decreased with the increase of E2. Consistent with previous studies, this suggests that E2 has a direct effect on LDL metabolism $[14,15]$. It may be that the reduction of E2 leads to a decrease in postmenopausal LDL receptors [10].

Interestingly, we also found significant negative correlation between levels of E2 and HDL-C. HDL is considered to be a protective factor for atherosclerosis, helping to degrade cholesterol from VLDL and chylomicron by reverse the transport of cholesterol from peripheral tissues to the liver. E2 can regulate the rate of synthesis of HDL structural apolipoprotein in the liver. It increases HDL by enhancing the rate of apoA-I and apoA-II synthesis [16]. There is huge discrepancy in the level of HDL in postmenopausal women. Some studies have shown a significant decrease in HDL levels in postmenopausal women, while some studies have shown a significant increase in HDL levels $[10,17]$. The result of this difference may be due to variation in the study population, life interventions, and duration of menopause. On the other hand, HDL has different types of subtypes. Studies showed that the severity of CHD was correlated with the distribution of HDL subtypes. Large particles of HDL2b significantly decreased, while small particles of pre $\beta 1-H D L$ and HDL3 increased [18-20]. The level of the HDL3 subtype in female postmenopausal women is higher than that before menopause, suggesting that sex hormones may affect the distribution of HDL subtypes, which may be related to the rapid increase in the CVD risk in women after menopause. Furthermore, the study on HDL in the eldest Jews and their offspring in northern Europe also demonstrated that the diameter of HDL particles was larger, indicating that genetic factors influence the distribution of HDL subtypes [21]. However, we did not test the subtype of HDL, which is a limitation of this study. We need to perform further studies to understand the role of HDL in female centenarians.

Hypertension is one of the major risk factors of CVD. Our result indicated the incidence of hypertension decreased with the increase of E2, especially in stage 2 hypertension. Studies have found that E2 has multiple protective effects on the cardiovascular system [22, 23]. Our results are agreement with these studies. This is because E2 can inhibit vasoconstriction in response to acetylcholine as well as reduce the level of endothelin to dilate vessels [24]. Also, E2 can improve blood rheology through the nitric oxide pathway and play a protective role in blood vessels [25]. Studies have shown that E2 can directly act on vascular EC to enhance NO production through both genomic stimulation of eNOS expression [26, 27] and membrane receptor-mediated, non-genomic activation of the enzymatic activity. Furthermore, E2 may increase the release of PGI 2, a potent inhibitor of platelet aggregation and strong vasodilator [28]. In addition, E2 increases the production of endothelium-derived hyperpolarizing factor (EDHF), which activates $\mathrm{K}+$ channels, causes hyperpolarization, and in turn inhibits $\mathrm{Ca} 2$ + influx and causes VSM relaxation [29].

\section{Limitations of the study}

Due to number of subjects, the generalizability of the results is limited. Second, we did not test the subtype of HDL, which is a limitation of this study. We need to perform further studies to understand the role of HDL in female centenarians. Third, the study is only a cross-sectional study. We can not rule out the possibility of withdrawal bias in the annual follow-up of this large sample of centenarians.

\section{Conclusion}

This study examined the relationship between E2 and CVD risk factors in a group of community-based female centenarians. A negative correlations between serum E2 levels and CVD risk factors, i.e. high level of LDL-C, TC, and hypertension were observed in this population. Besides, the level of serum E2 is also negatively correlated with HDL-C. Further studies on the correlation between serum E2 and CVD risk factors, especially dyslipidemia, in longevous and post-menopausal women were warranted.

\section{Abbreviations \\ BMI: Body mass index; CVD: Cardiovascular disease; DBP: Diastolic blood pressure; E2: Oestradiol; HC: Hip circumference; HDL-C: High-density lipoprotein cholesterol; LDL-C: Low-density lipoprotein cholesterol; SBP: Systolic blood pressure; TC: Total cholesterol; TG: Triglyceride; WC: Waist circumference; WHR: Waist-hip ratio}

\section{Acknowledgements}

We appreciate all the participants of the Hainan Centenarian Study for their continued cooperation.

\section{Funding}

This study was funded by Key Research and Development Project of Hainan (grant nos. ZDYF2016135 and ZDYF2017095), and Hainan Natural Science Foundation (grant nos.817360). There is no role of the funding body in the design of the study and collection, analysis, and interpretation of data and in writing the manuscript.

\section{Availability of data and materials}

The datasets used and analyzed during the current study are available from the corresponding author on reasonable request.

\section{Authors' contributions}

ZQ designed the study and drafted the manuscript. YY, LFX, LL, LQ and WN participated in the design of the study and performed the investigation. NCX performed the statistical analysis. CXP performed the data input and sample management. ZF and ZYL conceived of the study, participated in its design and coordination, and helped to draft the manuscript. The authors declare that they have no conflict of interest. All authors read and approved the final manuscript. 


\section{Ethics approval and consent to participate}

Prior to investigation and physical examination, we have got the consent from the participants or from their family members such as sons and daughter-in-laws. If the participants could not sign their names because of illiteracy or being cognitive-impaired, their names were signed by their direct relatives after the consent of the participants. The Ethics Committee of the Hainan branch of PLA General Hospital (Sanya, Hainan) approved the study protocol (No. of serial: 301HNLL-2016-01)

\section{Consent for publication}

Not applicable.

\section{Competing interests}

On behalf of all authors, the corresponding author states that there is no conflict of interest.

\section{Publisher's Note}

Springer Nature remains neutral with regard to jurisdictional claims in published maps and institutional affiliations.

\section{Author details}

${ }^{1}$ Hainan branch of PLA General Hospital, Sanya 572000, China. ${ }^{2}$ Center for Healthy Aging and Development Studies, National School of Development, Peking University, Beijing, China.

Received: 1 May 2018 Accepted: 7 May 2019

Published online: 16 May 2019

\section{References}

1. Martin P, Gondo Y, Arai Y, Ishioka Y, Woodard JL, Poon LW, Hirose N. Physical, sensory, and cognitive functioning among centenarians: a comparison between the Tokyo and Georgia centenarian studies. Qual Life Res. 2018;27(11):3037-46

2. Arnold J, Dai J, Nahapetyan L, Arte A, Johnson MA, Hausman D, Rodgers WL, Hensley R, Martin P, Macdonald M, et al. Predicting successful aging in a population-based sample of Georgia centenarians. Curr Gerontol Geriatr Res. 2010

3. Austad SN, Bartke A. Sex differences in longevity and in responses to antiaging interventions: a mini-review. Gerontology. 2015;62(1):40-6.

4. Collins P, Rosano G, Casey C, Daly C, Gambacciani M, Hadji P, Kaaja R, Mikkola T, Palacios S, Preston R, et al. Management of cardiovascular risk in the perimenopausal women: a consensus statement of European cardiologists and gynecologists. Climacteric. 2007;10(6):508-26.

5. Muntner P, Shimbo D, Carey RM, Charleston JB, Gaillard T, Misra S, Myers MG, Ogedegbe G, Schwartz JE, Townsend RR, et al. Measurement of blood pressure in humans: a scientific statement from the American Heart Association. Hypertension. 2019:HYP0000000000000087.

6. Perls T, Kunkel L, Puca A. The genetics of aging. Curr Opin Genet Dev. 2002; 12(3):362-9.

7. Artan M, Hwang AB, Lee SV, Nam HG. Meeting report: international symposium on the genetics of aging and life history II. Aging (Albany NY). 2015;7(6):362-9

8. Yang WYHLM. The relationship of human life-span heredity and environment. Journal of Xinyang Teachers College. 1998.

9. Chen R, Lin SQ, Lin X, Chen Y, Yang QH, Zhou Y, Zhang Y. Effect of age on body composition in healthy Beijing womenZhonghua fu chan ke za zhi. 2008;43(1):36-40.

10. Pardhe BD, Ghimire S, Shakya J, Pathak S, Shakya S, Bhetwal A, Khanal PR, Parajuli NP. Elevated cardiovascular risks among postmenopausal women: a community based case control study from Nepal. Biochem Res Int. 2017; 2017:3824903

11. Napoli C. Oxidation of LDL, atherogenesis, and apoptosis. Ann N Y Acad Sci. 2003:1010:698-709.

12. Gao P, Wang XM, Qian DH, Qin ZX, Jin J, Xu Q, Yuan QY, Li XJ, Si LY. Induction of oxidative stress by oxidized LDL via meprinalpha-activated epidermal growth factor receptor in macrophages. Cardiovasc Res. 2013; 97(3):533-43.

13. Squadrito F, Altavilla D, Morabito N, Crisafulli A, D'Anna R, Corrado F, Ruggeri P, Campo GM, Calapai G, Caputi AP, et al. The effect of the phytoestrogen genistein on plasma nitric oxide concentrations, endothelin-
1 levels and endothelium dependent vasodilation in postmenopausal women. Atherosclerosis. 2002:163(2):339-47.

14. Hagberg JM, McCole SD, Ferrell RE, Zmuda JM, Rodgers KS, Wilund KR, Moore GE. Physical activity, hormone replacement therapy and plasma lipoprotein-lipid levels in postmenopausal women. Int J Sports Med. 2003; 24(1):22-9.

15. Barua L, Faruque M, Chandra Banik P, Ali L. Physical activity levels and associated cardiovascular disease risk factors among postmenopausal rural women of Bangladesh. Indian Heart J. 2018;70(Suppl 3):S161-6.

16. Szafran $\mathrm{H}$, Smielak-Korombel $\mathbf{W}$. The role of estrogens in hormonal regulation of lipid metabolism in women. Przegl Lek. 1998;55(5):266-70.

17. Derby CA, Crawford SL, Pasternak RC, Sowers M, Sternfeld B, Matthews KA. Lipid changes during the menopause transition in relation to age and weight: the study of Women's health across the nation. Am J Epidemiol. 2009:169(11):1352-61.

18. Filippatos TD, Rizos EC, Tsimihodimos V, Gazi IF, Tselepis AD, Elisaf MS. Small high-density lipoprotein (HDL) subclasses are increased with decreased activity of HDL-associated phospholipase a (2) in subjects with prediabetes. Lipids. 2013;48(6):547-55.

19. Tian L, Long S, Li C, Liu Y, Chen Y, Zeng Z, Fu M. High-density lipoprotein subclass and particle size in coronary heart disease patients with or without diabetes. Lipids Health Dis. 2012;11:54.

20. Freedman DS, Otvos JD, Jeyarajah EJ, Barboriak JJ, Anderson AJ, Walker JA. Relation of lipoprotein subclasses as measured by proton nuclear magnetic resonance spectroscopy to coronary artery disease. Arterioscler Thromb Vasc Biol. 1998:18(7):1046-53.

21. Barzilai N, Atzmon G, Schechter C, Schaefer EJ, Cupples AL, Lipton R, Cheng S, Shuldiner AR. Unique lipoprotein phenotype and genotype associated with exceptional longevity. Jama. 2003;290(15):2030-40.

22. Mullick AE, Walsh BA, Reiser KM, Rutledge JC. Chronic estradiol treatment attenuates stiffening, glycoxidation, and permeability in rat carotid arteries. Am J Phys Heart Circ Phys. 2001;281(5):H2204-10.

23. Christian RC, Harrington S, Edwards WD, Oberg AL, Fitzpatrick LA. Estrogen status correlates with the calcium content of coronary atherosclerotic plaques in women. J Clin Endocrinol Metab. 2002;87(3):1062-7.

24. Lee TM, Chou TF, Tsai CH. Differential role of K (ATP) channels activated by conjugated estrogens in the regulation of myocardial and coronary protective effects. Circulation. 2003;107(1):49-54.

25. Tsuda K, Kinoshita Y, Kimura K, Nishio I, Masuyama Y. Electron paramagnetic resonance investigation on modulatory effect of 17beta-estradiol on membrane fluidity of erythrocytes in postmenopausal women. Arterioscler Thromb Vasc Biol. 2001:21(8):1306-12.

26. MacRitchie AN, Jun SS, Chen Z, German Z, Yuhanna IS, Sherman TS, Shaul PW. Estrogen upregulates endothelial nitric oxide synthase gene expression in fetal pulmonary artery endothelium. Circ Res. 1997;81(3):355-62.

27. Chen Z, Yuhanna IS, Galcheva-Gargova Z, Karas RH, Mendelsohn ME, Shau PW. Estrogen receptor alpha mediates the nongenomic activation of endothelial nitric oxide synthase by estrogen. J Clin Invest. 1999:103(3):401-6.

28. Khalil RA. Estrogen, vascular estrogen receptor and hormone therapy in postmenopausal vascular disease. Biochem Pharmacol. 2013;86(12):1627-42.

29. Orshal JM, Khalil RA. Gender, sex hormones, and vascular tone. Am J Physiol Regul Integr Comp Physiol. 2004;286(2):R233-49.

Ready to submit your research? Choose BMC and benefit from

- fast, convenient online submission

- thorough peer review by experienced researchers in your field

- rapid publication on acceptance

- support for research data, including large and complex data types

- gold Open Access which fosters wider collaboration and increased citations

- maximum visibility for your research: over $100 \mathrm{M}$ website views per year

At $\mathrm{BMC}$, research is always in progress.

Learn more biomedcentral.com/submissions 